\title{
A GIS technology based potential eco-risk assessment of metals in urban soils in Beijing, China
}

\author{
Meie Wang ${ }^{\mathrm{a}}$, Yanying Bai ${ }^{\mathrm{b}}$, Weiping Chen ${ }^{\mathrm{a}, *}$, Bernd Markert ${ }^{\mathrm{c}, 1}$, Chi Peng ${ }^{\mathrm{a}}$, Zhiyun Ouyang ${ }^{\mathrm{a}}$ \\ a State Key Laboratory of Urban and Regional Ecology, Research Centre for Eco-Environmental Sciences, Chinese Academy of Sciences, Beijing 100085, China \\ ${ }^{\mathrm{b}}$ Institute of Geographic Sciences and Natural Resources Research, Chinese Academy of Sciences, Beijing 100101 11A, Datun Road, Chaoyang District, Beijing 100101, China \\ ${ }^{\mathrm{c}}$ Former Director of the Internationales Hochschulinstitut Zittau, Lehrstuhl für Umweltverfahrenstechnik, Markt 23, 02763 Zittau, Germany
}

\section{A R T I C L E I N F O}

\section{Article history:}

Received 19 May 2011

Received in revised form

19 September 2011

Accepted 27 September 2011

\section{Keywords:}

Heavy metal

Ecological risk

Urban soil

GIS

\begin{abstract}
A B S T R A C T
Ecological risks of heavy metals in urban soils were evaluated using Beijing, China as an example. Cadmium, $\mathrm{Cu}, \mathrm{Zn}, \mathrm{Pb}, \mathrm{Cr}$ and $\mathrm{Ni}$ contents of 233 surface soils sampled by 1 min latitude $\times 1$ min longitude grid were used to identify their spatial distribution patterns and potential emission sources. Throughout the city, longer the duration of urbanization greater was the accumulations of heavy metals especially, $\mathrm{Cd}, \mathrm{Cu}, \mathrm{Pb}$, and $\mathrm{Zn}$. The soil $\mathrm{Zn}$ mainly came from the wears of vehicular tires. Point source emissions of heavy metals were few and far in the downwind south-east quadrant of Beijing. The calculated risk indices showed potential median eco-risks in the ancient central city. No potential high eco-risk due to soil-borne heavy metals was found. The potential medium eco-risk areas in Beijing would expand from the initial 24 to $110 \mathrm{~km}^{2}$ if soil $\mathrm{pH}$ were to reduce by 0.5 units in anticipation.
\end{abstract}

() 2011 Elsevier Ltd. All rights reserved.

\section{Introduction}

Soils and the vegetation they support have important socioecological functions in urban environment, modulating flows of water, nutrients, heat, and fugitive emissions. Through these processes, urban pollutants such as heavy metals may be captured and attenuated in the soils (Mellor, 2001; Madrid et al., 2002; Morton-Bermea et al., 2009). Of which, industrial wastes, vehicular emissions, fugitive discharges of coal burning power generating stations are notable anthropogenic sources. Green spaces in turn provide aesthetically pleasing shelters and recreational opportunities for the hectic urban life. Modern cities in China are interspersed with densely inhabited neighborhoods and green spaces bringing residents into the close proximities where pollutants may accumulate. Where do the pollutants deposit with respect to their emission sources? Is there a potential risk to harm the integrity of urban soil ecosystem? Where will be the most susceptible locations? It is imperative to learn how the pollutants are distributed in the urban settings (Zhang et al., 2008; Schröder 2006).

The geo-statistical techniques may facilitate identification of pollution sources and spatial distributions of released pollutants. They are ideal for evaluating interactions between released heavy

\footnotetext{
* Corresponding author.

E-mail address: wpchen@rcees.ac.cn (W. Chen).

1 Present address: Fliederweg 17, D-49733 Haren/Erica, Germany.
}

metals and receiving environment based on spatial information of emission sources, processes governing pollutant distribution, and population density (Poggio and Vrščaj, 2009). Such interactions are assessed by interpolating heavy metal concentrations over the city landscapes with digital information of traffic network, factory locations, emission sources, and/or topographic conditions which may affect the transport and spatial distributions of heavy metals (Poggio and Vrščaj, 2009). The outcomes will provide the scientific basis for better environmental assessment and management (Zhang et al., 2008). The spatial assessment and visualization of the eco-risks caused by heavy metal contamination of urban soils afford assessment of exposure pathways, exposed receptors, and risks. It is a diagnostic protocol in pinpointing the urban soil contamination and making urban planning options (Poggio and Vrščaj, 2009).

For decades, the heavy metal contents of surface soils in Beijing have been a subject of investigations at the provincial level (where Beijing was one of the cities), as an example of urban-rural fringe and for developments in suburban districts. The distributions of soil-borne heavy metals in the most populated and urbanized segment of the city, namely area inside the 5th ring road, however have not been comprehensively delineated. In the most recent decade, the land use patterns in central Beijing continued to change. Factories were relocated and farming lands were converted to residential or commercial uses. There was a need to reconcile how the past legacies of pollution might post potential risk of harms to present residents as land use patterns changed and populations redistributed. 
Most procedures used to assess ecological risks caused by heavy metals in soils originated from Hakanson method and Geoaccumulation Index method. Those procedures were based on the total heavy metal contents in soils. However, the eco-toxicity of heavy metals depended to a great degree on their bioavailability in soils and their toxicological factors and soil properties such as soil organic matter content and pH would influence the bioavailability of heavy metals in soils. Sauvé et al. (2000) developed a model to estimate the bio-available heavy metal content of soils based on soil $\mathrm{pH}$, total metal content, and soil organic matter. The soil property based assessment protocols were deemed effective (Poggio and Vrščaj, 2009).

We hypothesized that heavy metals accumulated in urban soils would present a potential risk to the urban ecosystem and we determined the spatial distribution soil-borne $\mathrm{Cd}, \mathrm{Cu}, \mathrm{Zn}, \mathrm{Pb}, \mathrm{Cr}$ and $\mathrm{Ni}$, tracked their respective sources of emission, and assessed the eco-environmental risks of heavy metal accumulation in central Beijing.

\section{Materials and methods}

\subsection{Study sites and soil sampling}

Metropolitan Beijing is organized into 6 roughly concentric squires centered at the Forbidden City and expanded outward. Each ring is bordered by a circular express road for automobiles. Our investigation included essentially the entire area inside of the 5th ring road where population is dense and traffic density is high. The study area covers 6 separate administrative districts of Beijing, i.e., Dongcheng and Xicheng, constituted the ancient city and located inside the 2nd ring road and Chaoyang, Haidian, Fengtai and Shijingshan surrounded the ancient city and had been expanding outward from the 2 nd to 5 th ring road (Fig. 1).

The study area was divided into 285 cells according to a 1 min of latitude by $1 \mathrm{~min}$ of longitude grid pattern of the city (approximately $1.9 \mathrm{~km}$ by $1.0 \mathrm{~km}$ ). One composite surface soil sample $(0-10 \mathrm{~cm})$ was obtained inside each cell by mixing five subsamples uniformly distributed within a representative $10 \mathrm{~m} \times 10 \mathrm{~m}$ open space (usually at a neighborhood park, public open space, or typical vegetated area inside the grid) in 2008. Totally, only 233 soil samples were obtained due to restricted accessibility as some locations. Among them, 25 represented public parks, 58 represented traffic areas, 38 represented schools and public areas, 28 represented agricultural areas, 15 represented industrial areas, and 69 represented residential areas (Fig. 1).
Table 1

The 1st and 2nd grade of Environmental Quality Standards for soils from the Ministry of Environmental Protection of P.R.C. (GB15618-1995).

\begin{tabular}{lllllll}
\hline & $\mathrm{Cu}$ & $\mathrm{Cr}$ & $\mathrm{Ni}$ & $\mathrm{Zn}$ & $\mathrm{Pb}$ & $\mathrm{Cd}$ \\
\hline 1st standard $(\mathrm{mg} / \mathrm{kg})$ & 35 & 90 & 40 & 100 & 35 & 0.2 \\
2nd standard $(\mathrm{mg} / \mathrm{kg}), \mathrm{pH}>7.5$ & 100 & 250 & 60 & 300 & 350 & 0.6 \\
\hline
\end{tabular}

\subsection{Chemical analysis}

Soils were air-dried and crushed to pass through a sieve of $2 \mathrm{~mm}$ openings. A quarter of each sieved specimen was further ground to pass through a sieve of $0.1 \mathrm{~mm}$ openings. Aliquots of $0.25 \mathrm{~g}$ finely ground soil were digested using a fouracid mixture containing $10 \mathrm{ml} \mathrm{HCl}, 5 \mathrm{ml} \mathrm{HNO}_{3}, 5 \mathrm{ml} \mathrm{HF}$, and $3 \mathrm{ml} \mathrm{HClO}_{4}$. Digested extracts were combined $1: 1$ with aqua regia and made up to $50 \mathrm{ml}$ with deionized water for analyses of $\mathrm{Cu}, \mathrm{Zn}, \mathrm{Cr}$, Ni using ICP-OES spectroscopy and further diluted to $250 \mathrm{ml}$ for analyses of $\mathrm{Cd}$ and $\mathrm{Pb}$ using ICP-MS spectroscopy.

\subsection{Quality assurance and quality control}

The national registered standard reference materials, GSS-1 (Geochemical Standard Soil) was included in chemical analyses. Recoveries were $89-103 \%$ for $\mathrm{Cu}$, 93- $110 \%$ for $\mathrm{Zn}, 90-111 \%$ for $\mathrm{Cr}, 88-101 \%$ for Ni, $95-101 \%$ for $\mathrm{Cd}$, and $98-110 \%$ for $\mathrm{Pb}$. Duplicates were analyzed on $10 \%$ of the soil samples and the standard deviations were within $\pm 5 \%$ of the mean. Reagent blanks were included with each batch of samples assayed.

\subsection{Calculation of ecological risk index of heavy metals}

The eco-risks of the soils were assessed employing a tiered approach (Weeks and Cornier, 2005; Li et al., 2008). The conceptual model entailed that ( $\mathrm{Li}$ et al., 2008):

$\mathrm{RI}=\sum E_{r}^{i}$

where RI denoted the cumulative risk index, $E_{r}^{i}$ was the potential ecological risk factor of $i$ th heavy metal element of the soil in which $i$ ranges from 1 to $n$ heavy metal elements included in the assessment. In turn, $E_{r}^{i}$ was evaluated that:

$E_{r}^{i}=T_{b}^{i} \times T_{e}^{i} \times C_{f}^{i}$

where $T_{b}^{i}$ was the toxicological efficiency of the $i$ th heavy metal element and was related to the bioavailability of heavy metals in soils in the following manner:

$T_{b}^{i}=\sqrt{R_{b}^{i} / P_{b}^{i}}$

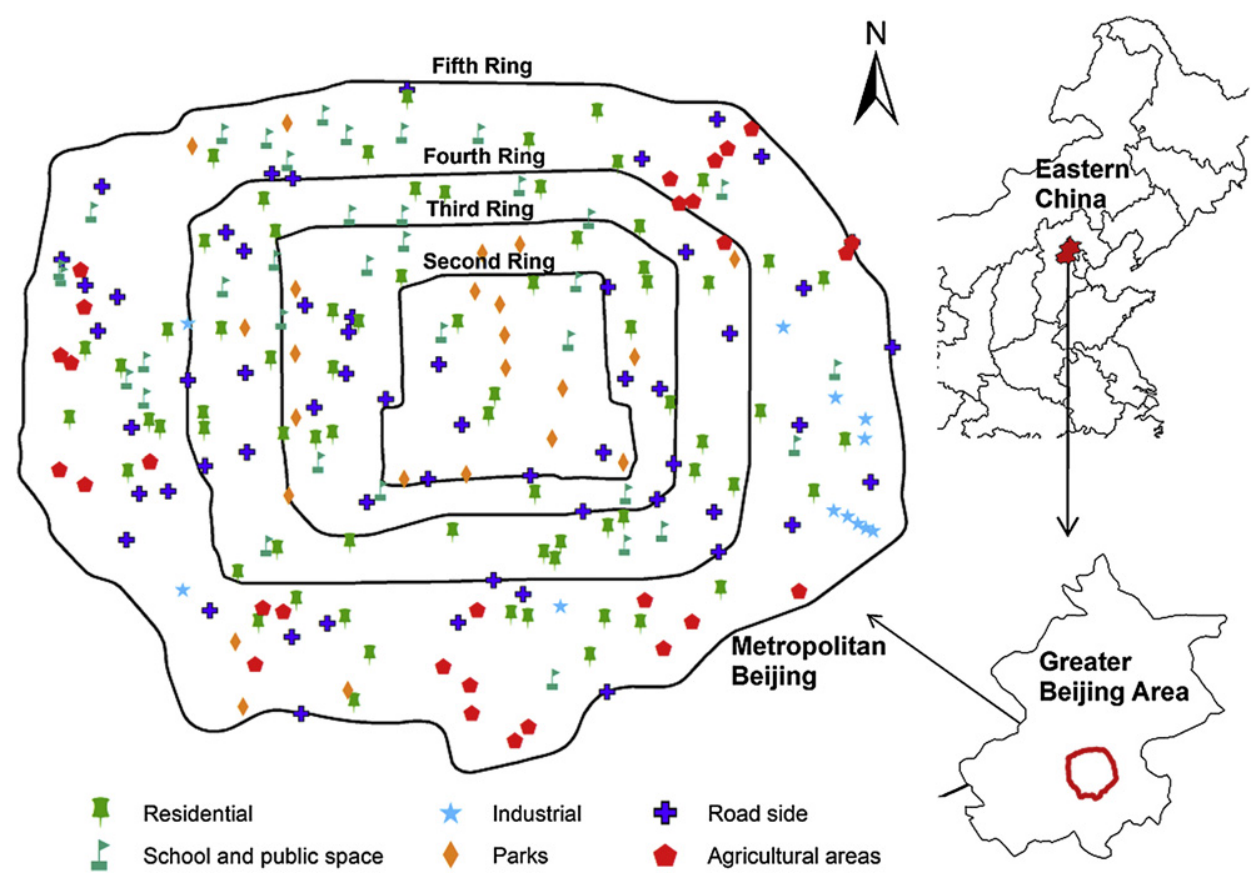

Fig. 1. Sample sites with different land uses in this study area. 
Table 2

$C_{R}^{i}, T_{e}^{i}, P_{r}^{i}$ of the standard material GSF-2 (Liu, 2006; Li et al., 2008).

\begin{tabular}{llll}
\hline Element & $C_{R}^{i}(\mathrm{mg} / \mathrm{kg})$ & $T_{e}^{i}$ & $P_{r}^{i}(\%)$ \\
\hline $\mathrm{Cd}$ & 0.206 & 15 & 20.2 \\
$\mathrm{Cu}$ & 44.9 & 2 & 1.84 \\
$\mathrm{~Pb}$ & 50.7 & 4 & 0.7 \\
$\mathrm{Cr}$ & 83.5 & 11 & 0.92 \\
$\mathrm{Ni}$ & 28.9 & 3 & 0.41 \\
$\mathrm{Zn}$ & 117 & 1 & 0.5 \\
\hline
\end{tabular}

where $R_{b}^{i}$ was the ratio of solution vs. total content of the $i$ th heavy metal in sampled soil expressed in percentage. $P_{b}^{i}$ was the ratio of solution vs. total content of the $i$ th heavy metal element of the baseline soils expressed in percentage (Table 2). $T_{e}^{i}$ was the toxicological weighing factor of the $i$ th heavy metal element relative to those of other heavy metal elements present (Table 2). $C_{f}^{i}$ was the ratio of the observed vs. baseline content of the $i$ th heavy metal:

$C_{f}^{i}=C_{D / C_{R}^{i}}^{i}$

where $C_{D}^{i}$ was the observed concentration of $i$ th heavy metal and $C_{R}^{i}$ was represented by the baseline concentration of the $i$ th heavy metal element in soils (Table 2). The concentrations of heavy metal content of soil solution were evaluated according to Sauvé et al. (2000) (Table 3).

Due to low soil $\mathrm{Ni}$ and $\mathrm{Cr}$ concentrations in comparison to the Environmental Quality Standards established by the State (Table 1) and lack of means to estimate dissolved $\mathrm{Ni}$ and $\mathrm{Cr}$ in soils, only $\mathrm{Cu}, \mathrm{Cd}, \mathrm{Pb}$ and $\mathrm{Zn}$ were included in the ecological risk assessment.

\subsection{Geo-statistical analysis}

Prior to analysis, the data were normalized by Box-Cox and logarithm transformation using Minitab 15 and Excel 2007. The normalized data was analyzed using ArcGIS 9.3. Cokriging interpolation was used to establish the spatial distributions of heavy metals in relation to the land uses, population density, and years since urbanization. Ordinary kriging with individual factors were produced for comparing outcomes of cokriging. The predictive spatial distribution map was generated based on outcomes of the interpolation technique that generated the smaller residua term. Potential ecological risk index was similarly interpolated. The areas of high potential eco-risk were adjusted according to soil pH using GIS.

Pollution hotspots were identified using local Moran's I. "Regional hotspots" (high values in a high value neighborhood), "individual hotspots" (a high value in a low value neighborhood) and "cool spots" (low values in a low value neighborhood) were delineated.

\section{Results and discussion}

\subsection{Spatial distribution of $\mathrm{Cr}$ and $\mathrm{Zn}$ in urban soils in Beijing}

For $\mathrm{Cr}$ and $\mathrm{Zn}$ in urban soils, the residuals resulting from cokriging related to population density, land uses and urbanization were significantly greater than that of ordinary kriging. It indicated that these three environmental factors had little significant impact on the distribution of $\mathrm{Cr}$ and $\mathrm{Zn}$ in urban soils. The spatial patterns of $\mathrm{Cr}$ and $\mathrm{Zn}$ over the urban landscape were interpolated by the ordinary kriging (Fig. 2).

The spatial distributions of $\mathrm{Cr}$ and $\mathrm{Zn}$ might be delineated according to the concentration in soils into three categories, namely the area of highest, middle, and lowest one-thirds of the respective concentration range. Within them, the regional hotspots, individual hotspots, and cool spots were identified. There was a well defined area of high soil $\mathrm{Cr}$ concentrations with a series of "regional hotspots" clusters distributing along the far west edge of the north-west quadrant and the south-west quadrant near the 5th ring road (Fig. 2a). They corresponded with the hilly region of Beijing where extractions of mineral materials have been taken place for centuries. The mountain soil belonging to the Brown soil series is predominant in this area whereas alluvial soil belonging to the Cinnamon soil series covers the flat lands of Beijing. The $\mathrm{Cr}$ contents of the mountainous soils were inherently higher than the alluvial deposits of the flat lands. Another high soil $\mathrm{Cr}$ concentration "regional hotspots" might be found at the south-west quadrant between the 2nd and 3rd ring roads where Liangshui River flowed through. It was one of the four urban water ways that for decades received unregulated and untreated wastewater discharges of Beijing and the water of the receiving body in turn had been used to irrigate the green spaces in this area. Liu et al. (2005) reported that the soil in areas irrigated with the river water showed significantly higher soil $\mathrm{Cr}$ contents than the surrounding areas indicative of the soil pollution. The Liangshui River now received exclusively reclaimed municipal wastewater and no longer was a source of heavy metal for the irrigated soils. Between the 4th and 5th ring roads, there are two "individual hotspots" located in the south-east and north-east quadrants, respectively. They represented a location of high soil $\mathrm{Cr}$ concentrations situated inside the low soil $\mathrm{Cr}$ concentration area. This "individual hotspot" in the south-east quadrant was a newly developed residential area that was an agricultural field known for production of spicy peppers, while the other hotspot was a stainless steel processing factory. Neither situation might be associated with the fugitive $\mathrm{Cr}$ release and pollution. Most likely, the $\mathrm{Cr}$ contents at these two locations again reflected the nature of indigenous soil minerals and there were little indication of significant $\mathrm{Cr}$ deposition from any point source discharge.

Area of the highest soil $\mathrm{Zn}$ contents were found in the city center that accounted for no more than 6\% Beijing. The $\mathrm{Zn}$ "regional hotspots" were also found in the vicinity. No specific attribute distinguished the regional hot spots from the surrounding areas. Beijing has been inhabited since the advent of written history in China four thousand years ago. The city center had been the capital of China since the 15th Century except a brief period of time. The overall high soil $\mathrm{Zn}$ contents in this area reflected the legacy left behind from the long history of human inhabitation. However, there were also more recent sources of $\mathrm{Zn}$ depositions. In fact, the soil $\mathrm{Zn}$ contents of more than $30 \%$ of the surface soil samples collected in Beijing exceeded the Environmental Quality Standards for soil Zn. There were 4 distinctive soil Zn "individual hotspots", namely the Lianhuachi Park, a park along the 3th ring road west; the stainless steel processing plant in the south-east quadrant along the 5th ring road; and two heavy traffic roadside locations. The wears of automobile tires were significant non-point sources for $\mathrm{Zn}$ accumulation in urban soils (Sadiq et al., 1989; Suzuki et al., 2009). We found the soil Zn

Table 3

Predicting models for dissolved concentrations of Cd, Cu, Pb and Zn (Sauvé et al., 2000).

\begin{tabular}{|c|c|c|}
\hline & Equations & $R^{2}$ \\
\hline $\mathrm{Cd}$ & $\log _{10}\left(\mathrm{DM}^{\mathrm{a}}\right)=-0.47 \pm 0.02 \mathrm{pH}+1.08 \pm 0.02 \cdot \log \left(\mathrm{TM}^{\mathrm{b}}\right)-0.81 \pm 0.05 \log \left(\mathrm{SOM}^{\mathrm{c}}\right)+3.42 \pm 0.11$ & $0.884^{* * \mathrm{~d}}$ \\
\hline $\mathrm{Cu}$ & $\log _{10}(\mathrm{DM})=-0.21 \pm 0.02 \mathrm{pH}+0.93 \pm 0.05 \cdot \log (\mathrm{TM})-0.21 \pm 0.02 \cdot \log (\mathrm{SOM})+1.37 \pm 0.14$ & $0.611^{* *}$ \\
\hline $\mathrm{Pb}$ & $\log _{10}(\mathrm{DM})=-0.37 \pm 0.04 \mathrm{pH}+0.56 \pm 0.07 \cdot \log (\mathrm{TM})+1.81 \pm 0.22$ & $0.347^{* *}$ \\
\hline $\mathrm{Zn}$ & $\log _{10}(\mathrm{DM})=-0.55 \pm 0.04 \mathrm{pH}+0.94 \pm 0.08 \cdot \log (\mathrm{TM})-0.34 \pm 0.12 \cdot \log (\mathrm{SOM})+3.68 \pm 0.31$ & $0.618^{* *}$ \\
\hline
\end{tabular}

\footnotetext{
a Soluble heavy metal contents $(\mathrm{mg} / \mathrm{L})$

b Soil organic matter contents (C\%).

c Soil heavy metal contents $(\mathrm{mg} / \mathrm{kg})$.

d At significant level of 0.01 .
} 


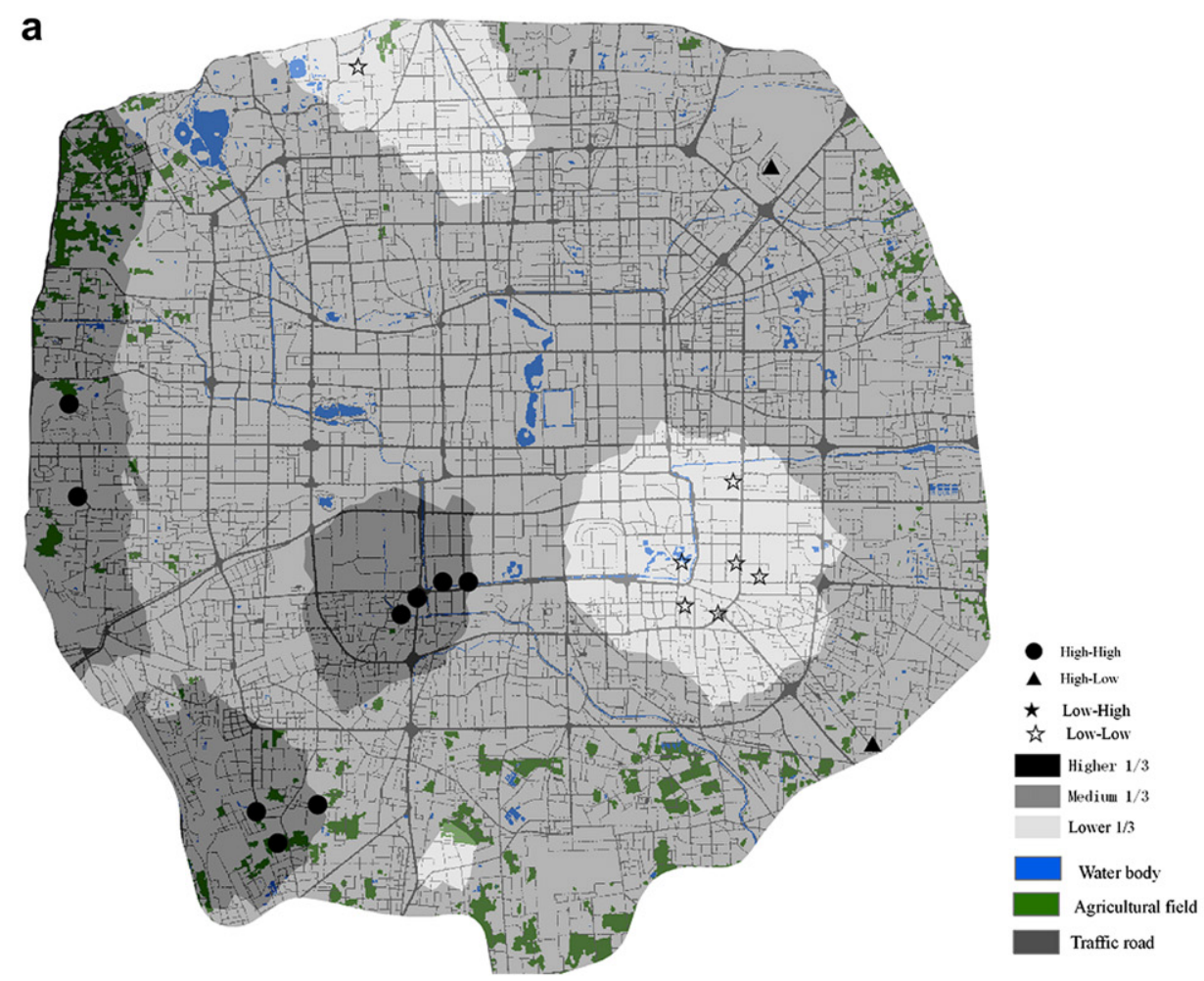

b

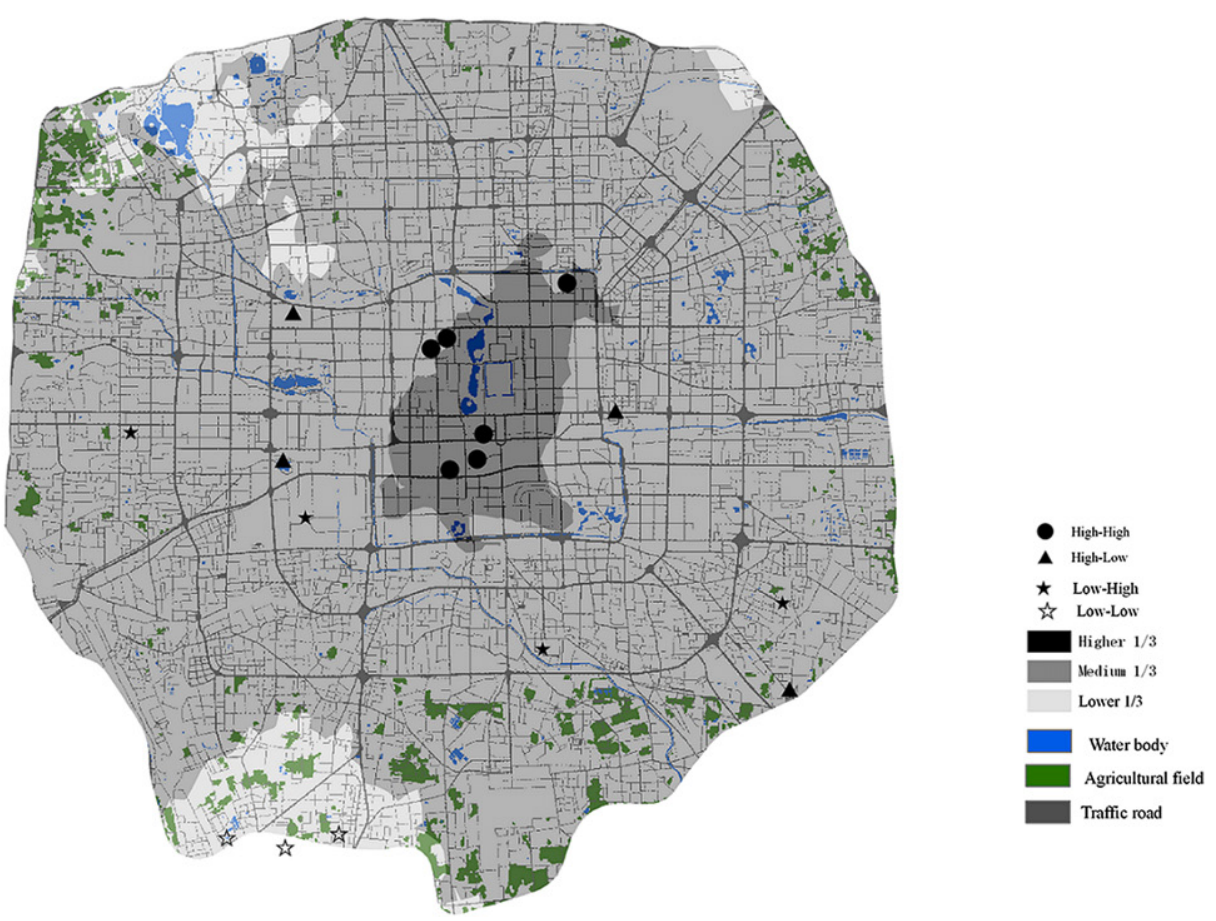

Fig. 2. Spatial distribution and pollution hotspot identification of $\mathrm{Cr}$ (a) and $\mathrm{Zn}$ (b) in Beijing urban soils.

concentrations of surface soil samples obtained at areas of high heavy automobile traffic volumes were significantly higher than those in areas of medium traffic volumes (Fig. 3). The non-point mobile source emissions caused the cross the board rise in soil $\mathrm{Zn}$ contents. In addition, the apparent point source discharges of the stainless steel processing factory had affected the soil $\mathrm{Zn}$ concentrations in a limited area.

\subsection{Spatial distribution and pollution hotspots identification of $\mathrm{Ni}$}

Based on the residues, the outcomes of cokriging and ordinary kriging of $\mathrm{Ni}$ were comparable in terms of their relationships to population density, land uses and urbanization age (Fig. 4). There was an area of high soil $\mathrm{Ni}$ concentrations in the north-west quadrant extending from the city center toward the 3rd ring road, 


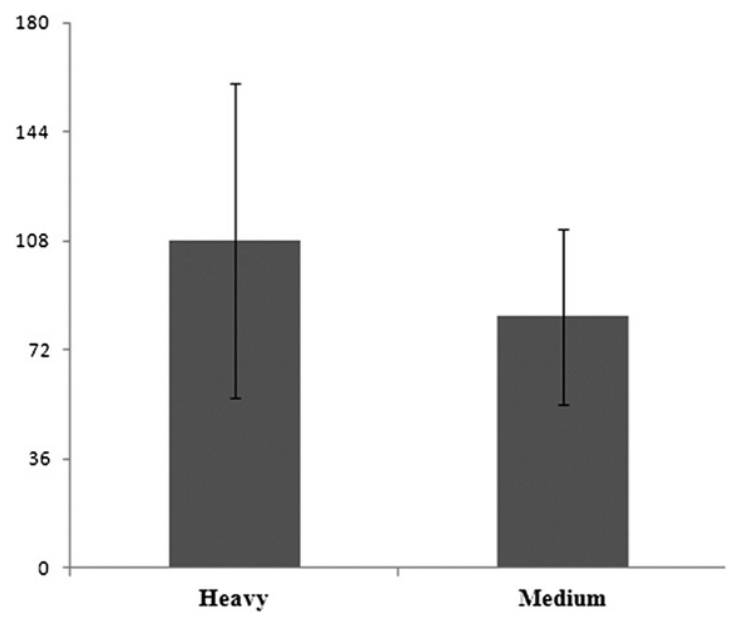

Fig. 3. Comparison of $\mathrm{Zn}$ concentration in surface soils between heavy traffic roadsides and medium traffic roadsides.

which covers the oldest part of Beijing. The high soil Ni concentrations in Beijing however did not appear to be historical relics.

There were three "individual hotspots" of Ni. Two were located in the low soil Ni concentration area in the south-west quadrant: one was a community park near the Liangshui River and the other was a newly completed World Park. The third "individual hotspot" was located in a ceramic factory. The community park was long irrigated with water of the Liangshui River making the park an "individual hotspot" in a low $\mathrm{Ni}$ concentration area. The soil $\mathrm{Ni}$ contents of the recently completed World Park came most likely from construction debris in building miniatures of noted landmarks around the world. There was also a "cool spot" located in the west-south quadrant that was a new development on originally virgin forest grounds.

\subsection{Spatial distribution and pollution hotspot identification of $\mathrm{Cd}, \mathrm{Pb}$ and $\mathrm{Cu}$}

For distributions of soil $\mathrm{Cd}, \mathrm{Pb}$ and $\mathrm{Cu}$, cokriging provided the best outcomes and the urbanization age showed the most significant impacts (Fig. 5). There were two separate areas of high soil Cd concentrations: one was the city center, footprint of the old city and the other in the north-west quadrant whose footprints covered the ruins of imperial gardens that was destroyed and burned by the invading arm forces of English and French in 1860 and has abandoned ever since and the nearby district where institutions of higher learning of Beijing congregated (Fig. 5a). Several "regional hotspots" were isolated. The soil profiles in these locations had seldom been disturbed. The high soil Cd levels represented in the case of the ruins impacts of destruction and deposition of ashes and debris and in the case of educational institutions accumulations from long period of inhabitation and anthropogenic activities.

There were several additional soil Cd "individual hotspots" that included the Lianhuachi, a park in the south-west quadrant along the 3 rd ring road. The small lake inside, Lianhuachi, was the center piece of the park and it has been in existence for 3000 years. The other soil $\mathrm{Cd}$ regional hot spot was a stainless steel processing factory in the south-east quadrant along the 5 th ring road. There were four "individual hotspots" located in the vicinities of heavy vehicular traffic. Multiple diffused and pointed sources, historical and more recent, has caused $\mathrm{Cd}$ to accumulated at various locations across the city.

Essentially, surface soils of the entire city center exhibited high $\mathrm{Pb}$ levels (Fig. 5b). There also were several "regional hotspots". The spatial distribution of $\mathrm{Pb}$ in Beijing reflected precisely the progression of the urban expansion, from the city center outward. The later urbanized west and west-south sectors between the 4th and 5th ring roads exhibited the lowest soil $\mathrm{Pb}$ concentrations concentration. Lead $(\mathrm{Pb})$ is a ubiquitous pollutant of the urban metropolis, ancient or modern (Vrščaj et al., 2008). The high soil Pb levels in old city area were indicative of the legacy showing long

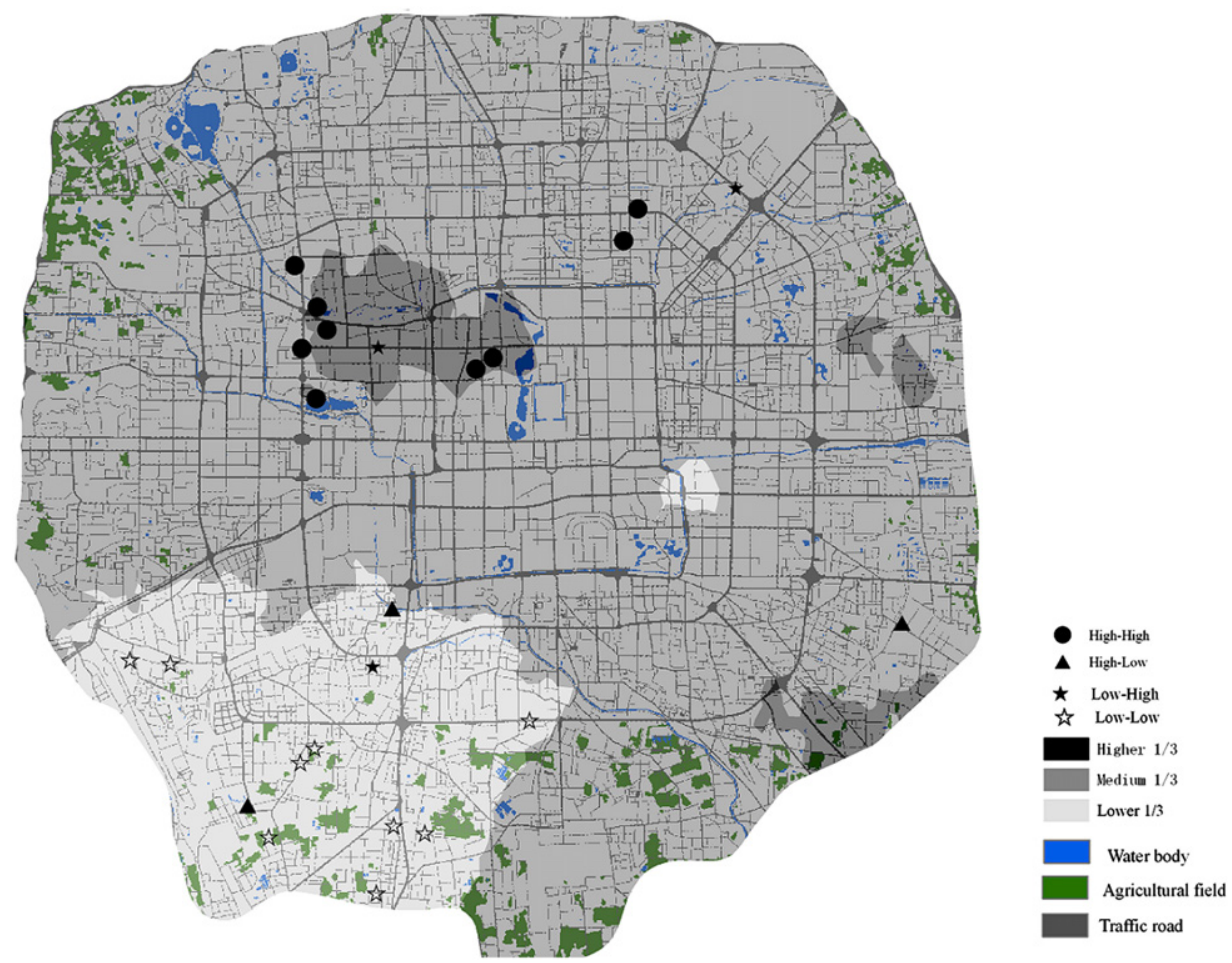

Fig. 4. Spatial distribution and pollution hotspots identification of $\mathrm{Ni}$ in Beijing urban soils. 

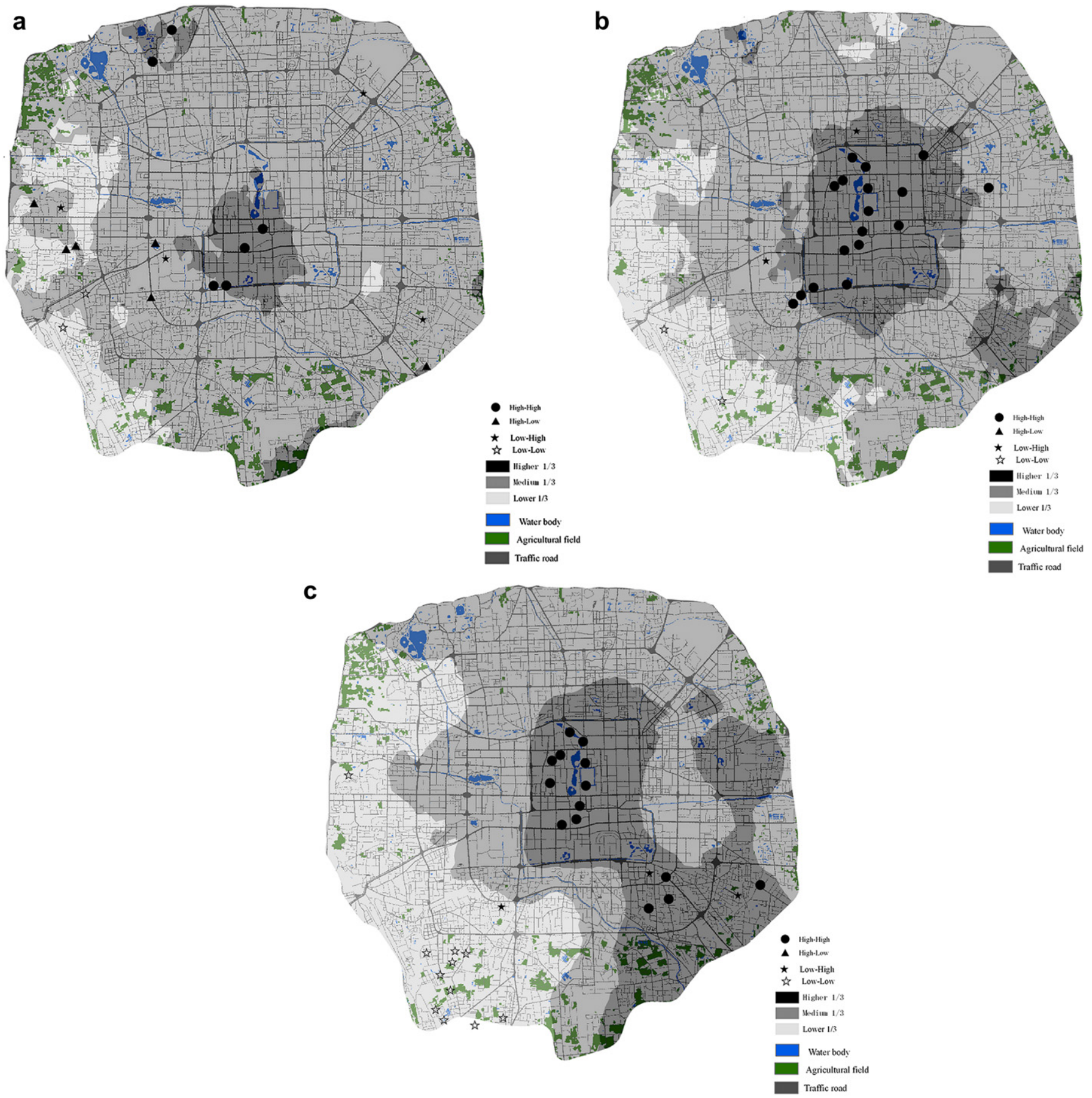

Fig. 5. Spatial distribution and pollution hotspot identification of $\mathrm{Cd}(\mathrm{a}), \mathrm{Pb}(\mathrm{b})$ and $\mathrm{Cu}(\mathrm{c})$ in Beijing urban soils.

history of human inhabitation, wars, destructions, and reconstructions (Fig. 5b). A lack of "individual hotspot" clearly showed little modern source $\mathrm{Pb}$ emissions in Beijing.

The areas with high soil $\mathrm{Cu}$ concentration were concentrated in the city center and the east-south quadrant (Fig. 5c). The city center area was characterized by overall elevated soil $\mathrm{Cu}$ concentrations and a dozen of $\mathrm{Cu}$ "regional hotspots", a combined results of diffused inputs over the history and more recent point sources emission of industries. Casting of bronze ritual and ceremonial objects, weapons, household utensils, and coins started over 4000 years ago. The low soil $\mathrm{Cu}$ concentration areas were toward the west end (between the 4 th and 5th ring roads) of north-west and south-west quadrants in which several "cool spots" were noted. This was the most recently urbanized section of Beijing. The spatial distribution map of soil $\mathrm{Cu}$ showed that the historical relics, industrial emissions caused elevated soil $\mathrm{Cu}$ concentrations in inner Beijing.

In the south-east quadrant, selected croplands had been used for land application of municipal wastewater up to the 1990s when sewage treatments gradually came online. More recently, it was the designated industrial zone where much of the city's production facilities had relocated (Liu et al., 2005; Fu et al., 2006; Hu et al., 2006; Zhu, 2001). The elevated soil $\mathrm{Cu}$ concentrations in this quadrant reflected the legacy of land applications. So far, no individual or regional hotspots were observed beyond the high $\mathrm{Cu}$ 
concentration areas signaling little point source $\mathrm{Cu}$ emissions from the recently established industrial production facilities.

\subsection{Ecological risk index of heavy metals}

Outcomes of cokriging showed that duration of urbanization was the single most important factor in determining the ecological risk,
RI, of heavy metal accumulation of soils in Beijing. Longer was the duration of urbanization, higher was the eco-risk of soil-borne heavy metals (Fig. 6a). The RIs of soils covered a wide range. Adopting the principle of always being conservative in risk assessment, the high end of the eco-risk range obtained was chosen for the delineated.

Based on the spatial distribution of RI (Fig. 6a), no high risk area was observed. There was however a small area of medium risk

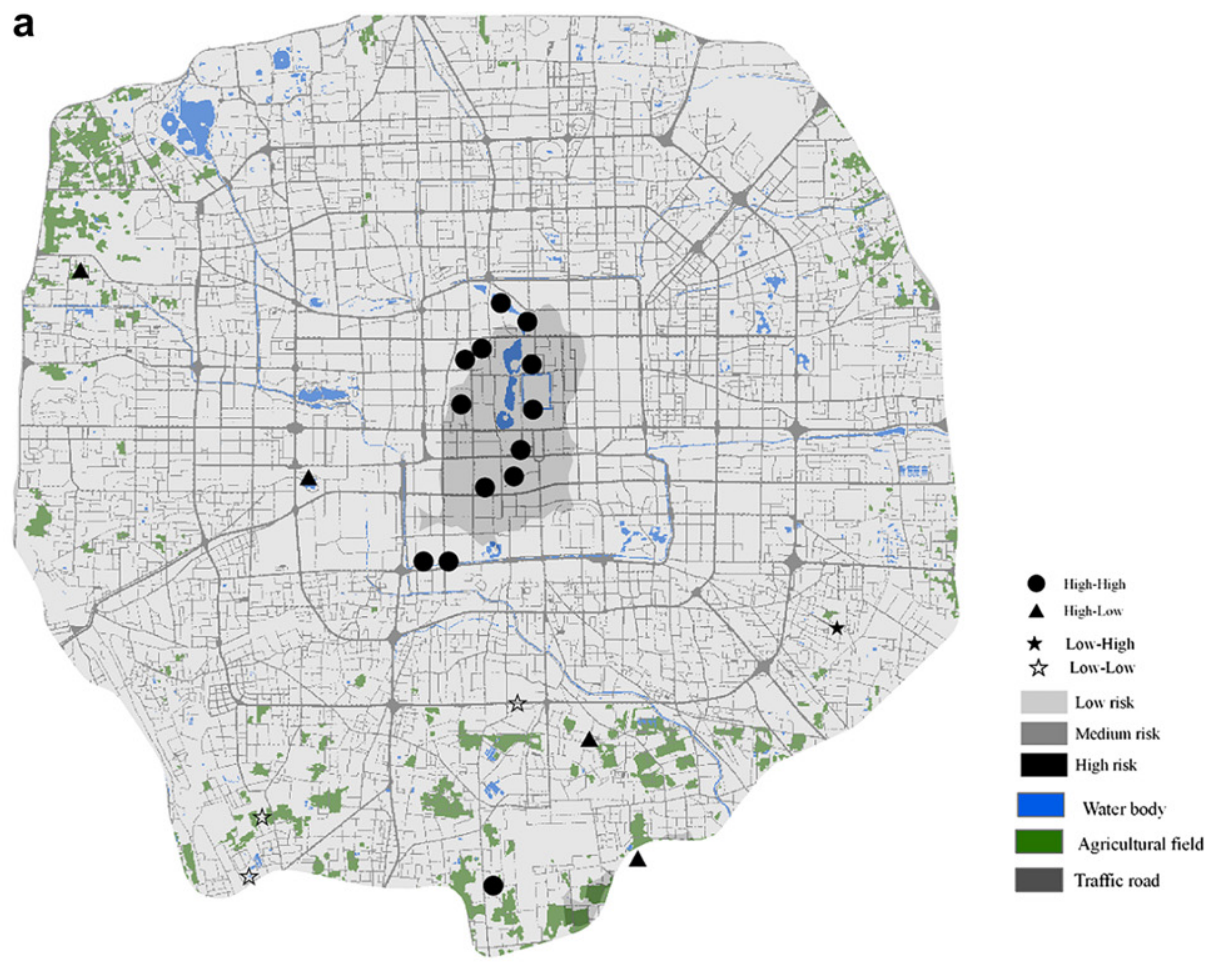

b

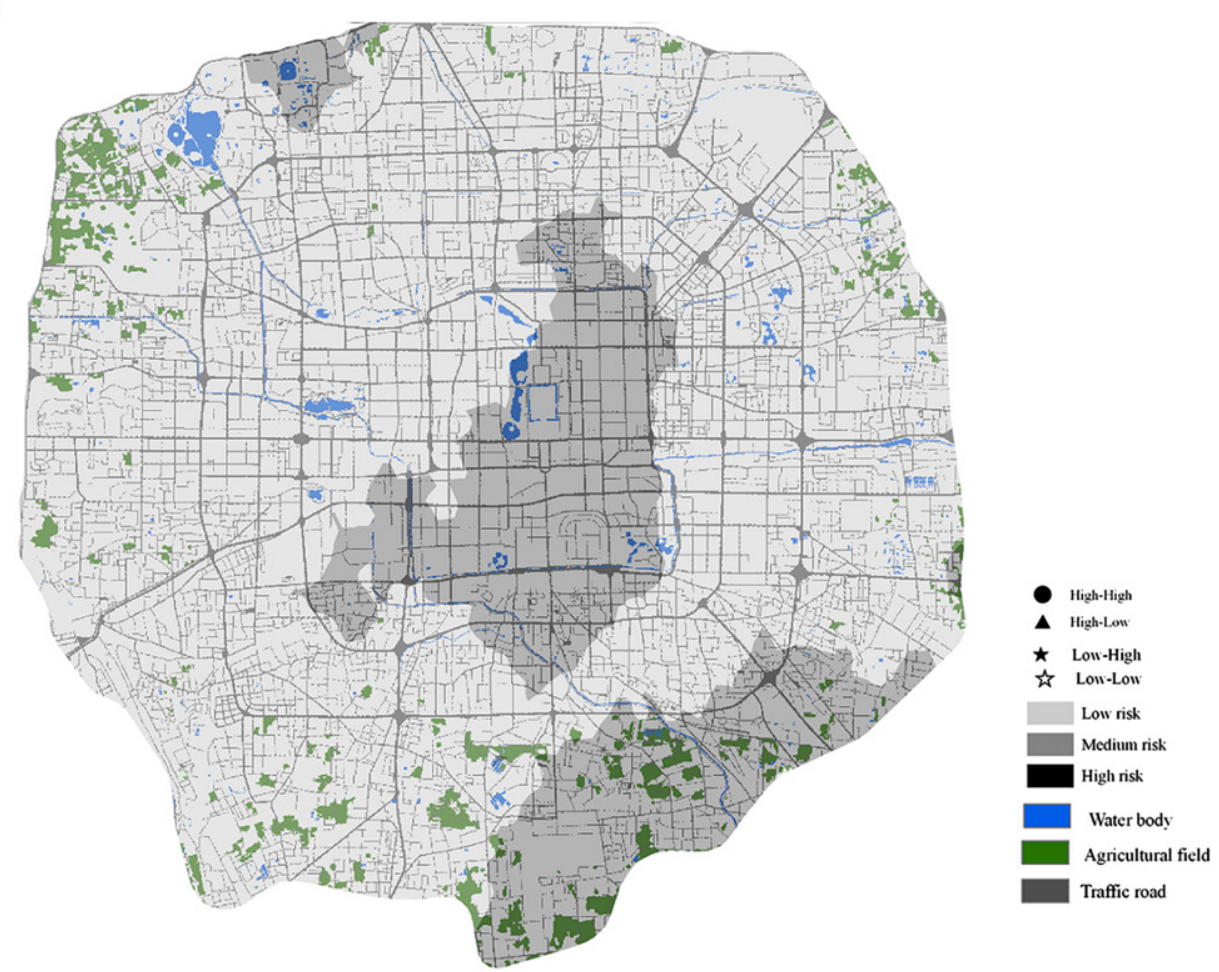

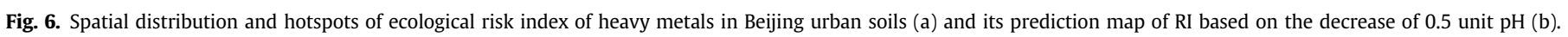


located in city center. In addition, a dozen of "regional hotspots" were found in the city center and a "regional hotspot" was located in a wood toward the south side of the city. There were four "individual hotspots" namely, the 3000-year Lianhuachi Park, a printing factory near the 4th ring road at south end of the city, and two locations in woods near the 5th ring road at the north-west and south end of the city, respectively. The pHs of soils at the two "individual hotspots" in woods were relatively low.

The parameters in Equations (1) through (3) that were used to calculate RI were sensitive to changes of soil $\mathrm{pH}$ that in turn might subject influences of acidic wet/dry depositions (Larssen and Carmichael, 2000). Since 2001, Beijing has experienced progressively acute acid precipitations. Acidic depositions were related to the vehicular and power generation emissions (Wang et al., 2010). With the ever increasing automobiles and traffic corridors in the city, we hypothesized that the $\mathrm{pH}$ of surface soils in Beijing could decrease considerably in the near future.

The eco-risks of heavy metals in surface soils of Beijing were down adjusted by $0.5 \mathrm{pH}$ unit (Fig. 6b). No high risk area was noted even with the assumed changes of soil $\mathrm{pH}$. However, the areas of medium RI risk expanded considerably. The expanded bands of medium RI risks appeared in the south-west and north-east quadrant inside the 3rd ring road, the south-west quadrant in between the 4th and 5th ring roads, and the ruins of imperial garden in the north-west quadrant. Relatively, the medium risk areas expanded from the initial $24 \mathrm{~km}^{2}$ to the expanded $110 \mathrm{~km}^{2}$ suggesting cautions on land use and soil management of the newly identified areas in those areas to avoiding soil quality deteriorations.

\section{Conclusions}

The spatial distribution of soil heavy element concentrations offered relevant information on species, sources, and extents of heavy metal accumulations in urban soils and permitted realistic assessment of the eco-risks of heavy metals in urban soils. The main conclusions are:

1) Legacies associated with long history of human inhabitation, wars, destructions, and reconstructions were the primary causes of heavy metal accumulation in the soils of old Beijing city center. The "regional hotspots" throughout and an "individual hotspot" at the 3000-year Lianhuachi Park were examples. Longer the duration of urbanization, greater heavy metal accumulations were found in the soils, especially for $\mathrm{Pb}, \mathrm{Cd}$ and $\mathrm{Cu}$.

2) Point source emissions of heavy metals are few in Beijing urban areas inside the 5th road due to the policy of relocating existing factories and only permitting new industries in the downwind south-west quadrant of the city. At present, only a stainless steel processing factory in the south-east along the 5th ring road could be considered as a point emission source caused Cd and $\mathrm{Zn}$ metal concentrations of nearby soils to elevate.

3) The elevated soil $\mathrm{Cr}$ concentrations in Beijing was associated with the inherent soil parent materials of mountain brown soils that were higher $\mathrm{Cr}$ concentrations compared to the alluvial Cinnamon soils of the flat lands.

4) Except for the central city area, elevated $\mathrm{Zn}$ concentration of soils in Beijing were found in the vicinity of heavy volumes of vehicular traffic and the enrichments were caused by diffused emissions of $\mathrm{Zn}$ wearing off from vehicle tires.

5) Risk Indices (RI) calculated in terms of total heavy metal content, soil $\mathrm{pH}$, and soil organic matter content offered realistic and integrated assessment of eco-risks of heavy metal accumulations in urban soils.

6) The distribution of RI in Beijing urban soils showed that despite of the apparent anthropogenic influences of the soil heavy metal contents in Beijing, no high eco-risk areas was observed. However, the old city exhibited medium eco-risks. According to the eco-risk prediction map, assuming the soil pH in Beijing would decrease over time due to progressively acute acidic wet and dry depositions, the areas of medium eco-risk would expand from the initial $24 \mathrm{~km}^{2}-110 \mathrm{~km}^{2}$ when the $\mathrm{pH}$ of soils in Beijing was down adjusted by $0.5 \mathrm{pH}$ unit. It identified areas critical in preventing further deterioration of the soil quality.

\section{Acknowledgments}

We gratefully acknowledged financial supports provided by the National Natural Science Foundation of China (Grant No. 41030744 and 41173123), the Knowledge Innovation Program of the Chinese Academy of Science (Grant No. KZCX2-YW-422), the Technical Supporting Programs of China (Grant No. 2007BAC28B01) and the Special Foundation of State Key Lab of Urban and Regional Ecology.

\section{References}

Fu, H., Wu, Y.H., Wei, L.H., 2006. Distribution and evaluation of heavy metals in agricultural soil in southern area of Beijing. Journal of Agro-Environment Science 25 (1), 182-185.

Hu, K.L., Zhang, F.R., Li, H., Huang, F., Li, B.G., 2006. Spatial patterns of soil heavy metals in urban-rural transition zone of Beijing. Pedosphere 16 (6), 690-698.

Larssen, T., Carmichael, G.R., 2000. Acid rain and acidification in China: the importance of base cation deposition. Environmental Pollution 110, 89-102.

Li, Z., Hou, J., Wang, J., 2008. Potential ecological risk assessment model for heavy metal contamination of agricultural soils in mining areas. Advances in Earth Science 23 (5), 509-516.

Liu mei, 2006. Soil reference materials of elemental forms in China, Thesis submitted to China University of Geosciences for the master degree of science.

Liu, W.H., Zhao, J.Z., Ouyang, Z.Y., Söderlund, L., Liu, G.H., 2005. Impacts of sewage irrigation on heavy metal distribution and contamination in Beijing, China. Environment International 31, 805-812.

Madrid, L., Barrientos, E.D., Madrid, F., 2002. Distribution of heavy metal contents of urban soils in parks of Seville. Chemosphere 49, 1301-1308.

Mellor, A., 2001. Lead and zinc in the Wallsend Burn, and urban catchment in Tyneside, UK. The Science of the Total Environment 269, 49-63.

Morton-Bermea, O., Hernández-Álvarez, E., González-Hernández, G., Romero, F. Lozano, R., Beramendi-Orosco, L.E., 2009. Assessment of heavy metal pollution in urban topsoils from the metropolitan area of Mexico City. Journal of Geochemical Exploration 101, 218-224.

Poggio, L., Vrščaj, B., 2009. A GIS-based human health risk assessment for urban green space planning-an example from Grugliasco (Italy). The Science of the Total Environment 407, 5961-5970.

Sadiq, M., Alam, I., EI-Mubarek, A., AI-Mohdhar, H.M., 1989. Preliminary evaluation of metal pollution from wear of auto tires. Bulletin of Environmental Contamination and Toxicology 42, 743-748.

Sauvé, S., Hendershot, W., Allen, H., 2000. Solid-solution partitioning of metals in contaminated soils: dependence on $\mathrm{pH}$, total metal burden, and organic matter. Environmental Science and Technology 34 (7), 1125-1131.

Schröder, W., 2006. GIS, geostatistics, metadata banking, and tree- based models for data analysis and mapping in environmental monitoring and epidemiology. International Journal of Medical Microbiology 296 (S1), 23-36.

Suzuki, K., Yabuki, T., Ono, Y., 2009. Roadside Rhododendron pulchrum leaves as bioindicators of heavy metal pollution in traffic areas of Okayama, Japan. Environmental Monitoring and Assessment 149, 133-144.

Vrščaj, B., Poggio, L., Marsan, F.A., 2008. A method for soil environmental quality evaluation for management and planning in urban areas. Landscape and Urban Planning 88, 81-94.

Wang, C., Wang, P., Liu, Z., 2010. The investigation of the soil $\mathrm{pH}$ along some highways in Beijing. Chinese Agricultural Science Bulletin 26 (1), 121-125.

Weeks, J.M., Cornier, S.D.W., 2005. Ecological risk assessment of contaminated soil Mineralogical Magazine 65 (5), 601-613.

Zhang, C., Luo, L., Xu, W., Ledwith, V., Poggio, L., 2008. Use of local Moran's I and GIS to identify pollution hotspots of $\mathrm{Pb}$ in urban soils of Galway, Ireland. The Science of the Total Environment 398, 212-221.

Zhu, G.Z., 2001. Pollution of heavy metals on soils in east-south area of Beijing and its remediation. Agro-Environmental Protection 20 (3), 164-166. 188. 